\title{
Effects of the $\mathrm{NK}_{1}$ Antagonist, Aprepitant, on Response to Oral and Intranasal Oxycodone in Prescription Opioid Abusers
}

\author{
Sharon L. Walsh, Ph.D. ${ }^{1,2,3}$, Markus Heilig, M.D., Ph.D. ${ }^{4}$, Paul A. Nuzzo, M.A. ${ }^{1}$, Pam \\ Henderson, B.S. ${ }^{1}$, and Michelle R. Lofwall, M.D. ${ }^{1,2,3}$ \\ ${ }^{1}$ Center on Drug and Alcohol Research, University of Kentucky, Lexington, KY \\ ${ }^{2}$ Department of Behavioral Science, University of Kentucky, Lexington, KY \\ ${ }^{3}$ Department of Psychiatry, University of Kentucky, Lexington, KY \\ ${ }^{4}$ National Institute on Alcohol Abuse and Alcoholism, Bethesda, MD
}

\section{Abstract}

Preclinical studies suggest that the $\mathrm{NK}_{1}$ receptor may modulate the response to opioids, with $\mathrm{NK}_{1}$ inactivation leading to decreased opioid reinforcement, tolerance and withdrawal. Aprepitant is a selective $\mathrm{NK}_{1}$ antagonist currently marketed for clinical use as an anti-emetic. This 6-week inpatient study employed a randomized, double-blind, double-dummy, within-subject, crossover design. Subjects ( $n=8 ; 6$ male/2 female) were healthy, adult volunteers who provided subjective and objective evidence of current prescription opioid abuse (without physical dependence) and underwent careful medical and psychiatric screening. Fifteen experimental conditions, consisting of one aprepitant dose $(0,40 \& 200 \mathrm{mg}$, p.o. given as a 2-hr pretreatment) in combination with one oxycodone dose (placebo, oral [20 \& $40 \mathrm{mg} / 70 \mathrm{~kg}]$ and intranasal [15 \& $30 \mathrm{mg} / 70 \mathrm{~kg}]$ ), were examined. Sessions were conducted at least 48 -hr apart and multi-dimensional measures were collected repeatedly throughout the 6-hour session duration. Oxycodone, by both routes of administration, produced significant dose-related effects on the predicted measures (e.g., subjective measures of abuse liability, respiratory depression, miosis). Pretreatment with aprepitant $(200 \mathrm{mg}$ ) significantly enhanced ratings of oxycodone subjective effects related to euphoria and liking and doubled the street value estimates for the highest test doses of oxycodone by both routes. Some objective measures (respiratory function, observer-rated opioid agonist effects) were similarly enhanced by pretreatment with the highest dose of aprepitant. All dose combinations were safely tolerated. These findings are discussed in the context of the potential utility of $\mathrm{NK}_{1}$ antagonists in the treatment of opioid use disorders.

Corresponding Author: Sharon L. Walsh, Ph.D., Center on Drug and Alcohol Research, 515 Oldham Court, Lexington, KY 40503, sharon.walsh@uky.edu, phone: 859-257-6485, fax: 859-257-5232.

This work was carried out at the Straus Behavioral Science Research Building, University of Kentucky, Center on Drug and Alcohol Research, 515 Oldham Court, Lexington, KY 40503.

Authors Contribution

SLW and MH were responsible for the study concept. SLW, MH and MRL were responsible for the study design. PH and PAN contributed to screening and recruitment of subjects, acquisition of the data, data analysis and development of graphics. SLW was responsible for interpretation of the analytic results and drafted the manuscript. All authors provided critical review of the manuscript for accuracy and important intellectual content. All authors critically reviewed content and approved the final version for publication. 


\section{Keywords}

Opioid; abuse liability; oxycodone; aprepitant; $\mathrm{NK}_{1}$ antagonist; substance $\mathrm{P}$

Substance P, a peptide of the tachykinin family (Herpfer and Lieb, 2005) is distributed throughout the central and peripheral nervous systems; it was associated early on with pain physiology due to its localization in small, unmyelinated sensory fibers in spinal cord and its high density concentration in the dorsal roots (von Euler and Gaddum, 1931). The $\mathrm{NK}_{1}$ receptor, which preferentially binds Substance P, is a Gq-coupled member of the 7transmembrane, G-protein-coupled receptor superfamily. $\mathrm{NK}_{1}$ receptor densities in the human nervous system are highest in spinal cord, striatum and brain regions involved in affect and reward, including the nucleus accumbens, amygdala, hippocampus and septum. The $\mathrm{NK}_{1}$ receptor is also highly expressed in lower brain nuclei, including the raphe, locus ceruleus, periaquaductal gray, midbrain nuclei (e.g., substantia nigra and pars reticulata) and distributed throughout various cortical regions (Hargreaves, 2002; Mai et al., 1986; Nomura, Shiosaka and Tohyama, 1987). The $\mathrm{NK}_{1}$ receptor system has been implicated in numerous behaviors, including nociception (Trang, Quirion and Jhamandas, 2005), vomiting reflexes (Rubenstein et al., 2006), affective dysfunction (including anxiety and depression) (Ebner and Singewald, 2006; Herpfer and Lieb, 2005; Santarelli et al., 2002) and pain perception (Birklein and Schmelz, 2008; Hill, 2002; King et al., 2005; Trang et al., 2005).

Numerous studies have now examined the interaction between $\mathrm{NK}_{1}$ receptor antagonism and opioid-related responses, including physical dependence, tolerance, analgesia and rewardrelated behavior. With regard to the role of substance $\mathrm{P}$ in the development and expression of physiological opioid dependence, one early study examined naloxone-precipitated withdrawal in rats rendered opioid dependent following a daily morphine-dosing regimen. Intracerebroventricular administration of a selective $\mathrm{NK}_{1}$ receptor antagonist, RP67580, decreased opioid withdrawal signs in response to naloxone administration (Maldonado, Girdlestone and Roques, 1993). Subsequent studies examined opioid dependence and withdrawal in the genetically modified $\mathrm{NK}_{1}$ knock-out mouse $\left(\mathrm{NK}_{1}-/-\right)$ in which the $\mathrm{NK}_{1}$ receptor is absent. $\mathrm{NK}_{1}-/-$ mice rendered dependent on morphine and then spontaneously withdrawn exhibited some opioid withdrawal signs but failed to show the prototypic withdrawal response (i.e., jumping) in contrast to the wildtypes (Murtra et al., 2000). Moreover, the $\mathrm{NK}_{1}-/-$ mice treated chronically with morphine failed to develop a conditioned place aversion in response to naloxone administration.

The $\mathrm{NK}_{1}$ knock-out mice are similar to the wildtype with respect to level of motor activity, exploratory behavior in the open field, acute nociceptive responses to both the tail flick and hot plate tests (De Felipe et al., 1998) and exhibit comparable distribution and functionality of the $т и$ opioid receptor system (De Felipe et al., 1998). However, unlike the wildtypes, NK-/- mice do not exhibit acute morphine-induced increased locomotor activity nor sensitization after chronic morphine exposure to the locomotor effects of morphine (Murtra et al., 2000; Ripley et al., 2002). Murtra and colleagues (2000) demonstrated that $\mathrm{NK}_{1}$ knock-out mice failed to develop a conditioned place preference (CPP) in response to the administration of morphine, but did develop CPPs for cocaine and food, suggesting that the 
deletion of the receptor selectively reduced the rewarding effects of opioid agonist administration (Murtra et al., 2000). Conversely, an early study demonstrated that direct microinjection of Substance $\mathrm{P}$ and its C-terminal fragments that retain affinity for the $\mathrm{NK}_{1}$ receptor supported the development of a CPP (Hasenohrl, Gerhardt and Huston, 1992), and this was blocked by pretreatment with naloxone (Hasenohrl, Gerhardt and Huston, 1991), suggesting that the rewarding effects of $\mathrm{NK}_{1}$ activation were mediated, in part, through opioid systems. Gadd and colleagues (2003) demonstrated that chemo-ablation (through the use of the selective neurotoxin, SP-saporin) of neurons expressing $\mathrm{NK}_{1}$ receptors in the amygdala reduced the locomotor-stimulating effects of acute morphine and attenuated morphine CPP, while the responses to cocaine on these same measures remained intact (Gadd et al., 2003). Finally, using an operant lever press self-administration model, the $\mathrm{NK}_{1}$ knock-out mice acquired food self-administration more readily compared to the wildtypes (i.e., higher response rate, higher number of reinforcers earned), but the knock-out mice selfadministered significantly fewer morphine infusions compared to the wildtypes, while cocaine self-administration was comparable (Ripley et al., 2002). These studies suggest that deletion or pharmacological blockade of the $\mathrm{NK}_{1}$ receptor may selectively diminish the response to opioids on an array of outcomes.

Potential clinical implications arising from these preclinical findings include the possibility that $\mathrm{NK}_{1}$ antagonists could be used to reduce the development of tolerance and/or physical dependence in patients taking opioids chronically (e.g., for pain) and/or that treatment with $\mathrm{NK}_{1}$ antagonists could diminish the reinforcing or abuse liability related effects of opioids. While more than 300 patents have been filed for chemical entities with $\mathrm{NK}_{1}$ receptor activity (Huang and Korlipara, 2010) and numerous candidate $\mathrm{NK}_{1}$ antagonists have been in development for target indications of anxiety and depression and, more recently, treatment of alcohol dependence (George et al., 2008), there is only one $\mathrm{NK}_{1}$ antagonist currently approved and marketed in the U.S. for oral use. Aprepitant, previously known as MK-869, is marketed by Merck as Emend ${ }^{\circledR}$ and has been widely used as an anti-emetic, principally for the treatment of chemotherapy-induced nausea and vomiting in cancer patients (Dando and Perry, 2004). Aprepitant has good oral bioavailability estimated at about 60-65\% after single dose administration (Majumdar et al., 2006). It exhibits first-order kinetics (Nakade et al., 2008), reaches peak maximum concentrations approximately $4 \mathrm{hr}$ after oral dosing and has an estimated half-life in plasma of approximately 9-13 hr (Majumdar et al., 2006). Thus, it is suitable for producing a sustained effect if given acutely and has sufficient duration of action to lend itself to chronic administration. The purpose of the present study was to examine the effects of aprepitant on the subjective and physiologic response to a prototypic mu opioid agonist in individuals with histories of prescription opioid abuse as a first proofof-concept test that $\mathrm{NK}_{1}$ antagonists may diminish the effects of opioids related to their abuse potential. Oxycodone, a now common drug of abuse, was chosen as the prototypic opioid and was tested after both oral and intranasal administration because these are both common routes of misuse associated but with different pharmacodynamic characteristics. 


\section{Materials and Methods}

\section{Participants}

Participants were adult volunteers who used prescription opioids illicitly for their nonanalgesic psychoactive effects but were not physically dependent on opioids at the time of the study. All subjects reported current illicit opioid use (confirmed by urinalysis during multi-day screening) and abuse by both the intranasal and oral routes of administration (two also reported opioid use by the intravenous route). Prior intranasal opioid abuse was an inclusion criterion for ethical reasons. An opioid negative urine sample was also required during screening in the absence of withdrawal symptoms to exclude physiological opioid dependence. Individuals who were seeking substance abuse treatment or successfully sustaining abstinence in the community were excluded. Subjects were carefully screened to eliminate those with seizure disorders, any nasal cavity obstruction, asthma or other respiratory disorders, head injury, hypertension, cardiovascular disease, abnormal ECG or physical dependence on any drug requiring medical detoxification (i.e., alcohol, benzodiazepines). All participants were determined to be in good physical and psychiatric health by medical history and physical examination, an electrocardiogram and laboratory tests and exam by a psychiatrist. Screening also included a structured interview using the Addiction Severity Index (ASI) (McLellan et al., 1992), the NEO (Costa and McCrae, 1985), SCL-90 (Derogatis, 1983), Beck Depression Inventory (Beck et al., 1961) and a literacy evaluation. Volunteers were recruited through local advertisements and were paid for their participation. The University of Kentucky Institutional Review Board approved this study, and subjects gave their written informed consent prior to participation. A Certificate of Confidentiality was obtained from the National Institute on Drug Abuse for the project. This study was conducted in accordance with the Helsinki guidelines for ethical human research.

A total of 15 subjects signed the screening consent form; nine were qualified to participate, signed study consent, and enrolled as inpatients. Of those, one left for personal reasons prior to receiving study drug, and the remaining 8 completed the study without any adverse events. Throughout the duration of their inpatient stay, volunteers were offered recreational materials when not undergoing testing, including an array of reading and puzzle books, inroom video gaming stations along with movies and television programming. Of the eight who completed ( 6 male, 2 female), all were Caucasian, with a mean ( \pm S.E.M.) age of 32.3 \pm 3 years and average education of 12.6 years $( \pm .57)$. Subjects reported using illicit opioids 9.5 ( \pm 1.7 days) of the preceding 30 days. Average reported age of first use of illicit opioids was $18.0( \pm 1.2)$ years with a lifetime history use of opioids of 8.9 years $( \pm 2.4)$. Subjects also reported current (last 30 day) use of cigarettes $(n=8)$, alcohol $(n=6)$, cocaine $(n=2)$, sedatives/hypnotics $(n=2)$ and marijuana $(n=7)$.

\section{Study Design and Setting}

This 6-week inpatient study employed a randomized, double-blind, double-dummy, withinsubject, placebo-controlled design. It was conducted at the Clinical Research Development and Operations Center (CR DOC), a closed research unit in the University of Kentucky hospital. Subjects participated in fifteen 6-hour (hr) experimental sessions scheduled thrice 
weekly (minimally $48 \mathrm{hr}$ apart). Urine specimens were collected daily throughout the inpatient stay and tested for illicit drugs, including methadone, cocaine, THC, benzodiazepines, morphine-derived opioids, amphetamine, barbiturates, methamphetamine (Multi-Drug Screen Test Dip Card; American Screen Corp., Louisiana), oxycodone (Single Oxy Dip Card; American ScreenCorp., Louisiana), buprenorphine (Single Dip Bup Card; American Screening Corp., Louisiana) along with breath testing for alcohol (Alcosensor, Alcoscan AL5000, Sentech, South Korea) to ensure the absence of recent illicit/contraband use. Females were tested for pregnancy during screening visits and just prior to the start of each session.

\section{Study Drugs}

This study was performed under an investigator-initiated Investigational New Drug Application $(\# 69,214)$ with the FDA. All study medications were stored and prepared in the University of Kentucky Investigational Pharmacy. Aprepitant (Emend ${ }^{\circledR}$ ) and its matched placebo were obtained from Merck, Sharpe and Dohme Corporation. Active tablets were provided in 40-mg strength. To maintain the study blind, five identical tablets were administered prior to each session as follows: placebo (5 matched placebo tablets), $40 \mathrm{mg}$ (1 40-mg tablet and 4 matched placebos), $200 \mathrm{mg}$ (5 40-mg tablets). Oxycodone hydrochloride powder (Spectrum Laboratory, Gardena, CA) was used to formulate the oral (p.o.) and intranasal (i.n.) doses. For oral dosing ( $20 \& 40 \mathrm{mg} / 70 \mathrm{~kg}$ ), oxycodone was weighed and loose-filled with lactose into identically appearing size 0 capsules (Health Care Logistics); placebo capsules contained lactose only. For intranasal doses $(15 \& 30 \mathrm{mg} / 70 \mathrm{~kg})$, the correct amount of powder was weighed, lactose was added to achieve a total volume of 60 $\mathrm{mg}$, and it was placed in a 1-gram glass vial. Intranasal placebo was $60 \mathrm{mg}$ of lactose only.

\section{Experimental Sessions}

Subjects were initially trained on all procedures after admission. They were maintained on a caffeine-free diet, allowed a light breakfast $2 \mathrm{hr}$ before session, and could smoke up to 30 minutes (min) before session. Nursing staff supervised the oral administration of the five capsules at 8:00 AM. Sessions began at 9:30 AM in an isolated testing room. After $30 \mathrm{~min}$ of baseline data collection, subjects were provided with both a capsule to swallow followed by powder for intranasal insufflation; these contained either placebo or oxycodone depending upon the test condition. After swallowing the capsule, subjects transferred the powder to a mirror, split the powder into two lines, and snorted one line through each nostril using a straw under staff supervision. Subjects completed computerized questionnaires using a keyboard and/or mouse. A trained research assistant used a keyboard to initiate tasks and to enter observer-rated measures. Data were collected for $5.5 \mathrm{hr}$ after drug administration. Table 1 details the timing of all pharmacodynamic measures.

\section{Physiological Measures}

Oxygen saturation, heart rate and blood pressure were collected every min using a Dinamap Non-Invasive Patient Monitor (GE Medical Systems, Tampa, FL) for 30 minute before and for $5.5 \mathrm{hr}$ after drug administration. Respiratory rate and end-tidal $\mathrm{CO}_{2}(\mathrm{~mm} \mathrm{Hg})$ were measured using a Capnograph (N85, Nellcor, Boulder, CO). Pupil diameter was determined using a pupillometer (NeurOptics, San Clemente, CA) in constant lighting conditions. 


\section{Subject and Observer-Rated Measures}

Subject-rated measures collected during session included: six visual analog scales (VAS) rated from 0 ("not at all") - 100 ("extremely")(Walsh et al., 2008); the Addiction Research Center Inventory (ARCI) short form (Martin et al., 1971); street value questionnaire; a 25item adjective checklist that encompassed the Agonist and Fraser scales (Fraser et al., 1961; Preston, Bigelow and Liebson, 1987) and an observer-rated opioid adjective rating scale (see Table 1). Before and after session, a side effects checklist was collected that assessed (on a scale from 0 [not at all] to 4 [extremely]) the following signs/symptoms described as potential side effects of aprepitant: drowsiness, nausea, constipation, lack of energy, headache, loss of appetite, diarrhea, fever and hiccups.

\section{Performance and Ocular Tasks}

The digit symbol substitution task (DSST) was used to measure information processing (McLeod et al., 1982). The Maddox-Wing test (Model CE0120, Clement Clarke Ltd., London, UK) was used to assess ocular exophoria or under convergence (Walsh et al., 2008). Critical flicker fusion threshold, a measure of temporal discrimination of a visual stimulus, was measured using an automated flicker fusion device (Model 12021, Lafayette Instrument, Lafayette, IN).

\section{Statistical Analysis}

Outcomes were initially analyzed as raw time course data (subjective and observer-rated measures) or baseline adjusted time course data (physiological measures). As the design was unbalanced (1 placebo condition, 3 intranasal and 3 oral oxycodone conditions), three-factor within-subject analyses of variance (ANOVA) with Proc Mixed to account for any missing data (aprepitant dose [3 levels] $\times$ oxycodone dose [3 levels] and time [intervals in Table 1]) were conducted for each route of administration to examine dose effects. Statistical comparisons were not made directly between the two routes of administration, as this was not a primary aim of the study. Physiological measures collected every min were first averaged across time to yield intervals (5-30 min) corresponding to collection of subjective reports. Area-under-the-curves scores (AUC) were derived from time course data and analyzed using 2-factor ANOVA (aprepitant dose [3 levels] $\times$ oxycodone dose [3 levels]). All analyses were conducted using SAS 9.1 for Windows and were considered significant when $\mathrm{p} \leq 05$.

\section{Results}

\section{Subject-rated Measures}

Participant ratings for the visual analog measure "How much do you LIKE the drug?" are shown in Figure 1 for all experimental conditions. These data illustrate the time action curves for the subjective response to oral (upper panel) and intranasal (lower panel) oxycodone administration (statistical outcomes in figure legend). As can be seen, oxycodone (when preceded by placebo pretreatment) produced dose-dependent increases in ratings of "liking," and the drug onset was more rapid following intranasal dosing compared to oral dosing. The calculated time-to-peak response occurred at approximately 63 and $88 \mathrm{~min}$ after 
intranasal and oral administration, respectively (this profile was similar to the other visual analogs). The duration of action for oxycodone by both routes was generally comparable with effects declining after $2 \mathrm{hr}$ and only modest effects remaining at the end of $5 \mathrm{hr}$. Pretreatment with aprepitant $(200 \mathrm{mg})$ increased ratings of "liking" for the highest doses of oxycodone (shown in right column), but this did not achieve statistical significance for the time course data.

Figure 2 illustrates the dose response curves for oxycodone and aprepitant shown as AUC values for "How high are you?" (upper row) and "Does the drug have any good effects?" (middle row). Oxycodone also significantly increased ratings of "any drug effect", "desire for opioids" (p.o. and i.n.) and bad effects (p.o. only; data not shown). There were significant main and/or interaction effects $(\mathrm{p}<.05)$ of aprepitant for these measures (except for bad effects and desire for opioids), whereby active aprepitant enhanced the ratings in response to oxycodone compared to oxycodone in combination with placebo. Also shown in Figure 2 (lower row) are participant estimates of street value (US\$) for the test doses of oxycodone. These were significantly and dose-dependently increased as a function of oxycodone dose regardless of route of administration. When given in combination with the highest dose of aprepitant ( $200 \mathrm{mg}$ ), street value estimates for the high doses of oxycodone by both routes were approximately doubled compared to when placebo aprepitant served as the pretreatment. The same figure reveals that aprepitant alone yielded a street value of zero.

The composite Agonist scale (Figure 3; upper panel) revealed significant and dosedependent effects for both aprepitant and oxycodone by both routes of administration (see figure legend for statistical outcomes). As shown, the profile of findings indicated that aprepitant significantly increased subject-rated scores in response to both oral and intranasal oxycodone. Scores for numerous individual adjective items (typical of $m и$ opioid agonist effects) were also significantly and dose-dependently ( $\mathrm{p}<.05)$ increased including: itchy, nodding, relaxed, talkative, dry mouth, drive, good mood, friendly (both routes), heavy (p.o. only), coasting and energetic (i.n. only). Only a few significant main and/or interaction effects with aprepitant were found for individual items, including itchy, nodding, good mood (p.o.) and nervous (i.n. only).

\section{Observer-rated Measures}

Observer ratings on numerous individual adjective scales sensitive to opioid agonist effects were both time- and dose-dependent with significant elevations in response to oral and intranasal oxycodone. For example, there were significant main effects of oxycodone dose $(\mathrm{p}<.05)$ on ratings of itchy, relaxed, talkative, drunken, good mood (p.o. \& i.n.), nodding, coasting, and heavy feeling (i.n. only). This pattern of findings was generally concordant with subject ratings on these same measures. Only ratings on "drunken" showed significant $(\mathrm{p}<.05)$ interactions with aprepitant (this was the case for both oral and intranasal oxycodone), whereby ratings were increased when the highest doses of oxycodone were given in combination with aprepitant ( $200 \mathrm{mg}$ ) compared to placebo aprepitant. Figure 3 (lower panel) illustrates the AUC data for the composite Agonist Scale for oxycodone. While these data were characterized by steeper oxycodone dose effect curves and higher scores overall for agonist ratings when active aprepitant doses were given compared to 
placebo, there were no statistically significant main or interaction effects for aprepitant (see figure legend for statistical outcome) in contrast to the composite scale results when rated by the subjects.

\section{Physiological Outcomes}

Analysis of the time course data revealed that oral and intranasal oxycodone produced significant decrements on all indices related to respiratory function (i.e., decreased oxygen saturation ( $\mathrm{p}<.001)$, increased end-tidal $\mathrm{CO}_{2}(\mathrm{p}<.001)$ and decreased respiratory rate $(\mathrm{p}<$. 001). There were also significant aprepitant by oxycodone interactions for both the oral $(\mathrm{F}[\mathrm{df} 4,28]=3.2 ; \mathrm{p}=.028)$ and intranasal routes $(\mathrm{F} 4,28]=6.8 ; \mathrm{P}=.001)$ on end-tidal $\mathrm{CO}_{2}$, which were characterized by the high dose of aprepitant increasing end-tidal $\mathrm{CO}_{2}$ especially in combination with the high doses of oxycodone. However, there were no statistically significant effects of aprepitant on oxygen saturation. There was a significant main effect of aprepitant on respiratory rate under the oral $(\mathrm{p}<.025)$ and intranasal $(\mathrm{p}=.005)$ challenge conditions, whereby respiratory rate was modestly lower under active aprepitant conditions compared to placebo. Findings for the AUC analyses were generally concordant with the time course outcomes, and representative data are shown in Figure 4 (upper panel) for endtidal $\mathrm{CO}_{2}$ (see figure legend for statistical outcomes). Importantly, there was no evidence of clinically significant respiratory depression under any test condition, and all drug combinations were safely tolerated.

Both oral and intranasal oxycodone produced dose- and time-dependent miosis $(\mathrm{p}<.001)$. While there was a trend for aprepitant to enhance the miotic effects of intranasal oxycodone observed in both the time course and AUC analyses (Figure 4; lower panel), there were no significant interactions with aprepitant on this outcome.

There were significant main effects of time for heart rate, systolic and diastolic blood pressure $(\mathrm{p}<.001)$ with each showing declines over the course of the experimental session under all conditions. For both oral and intranasal oxycodone ( $\mathrm{p}<.02)$, there were oxycodone $x$ time effects on systolic blood pressure; systolic pressure remained lower during the latter part of the sessions after active oxycodone compared to placebo. Finally, there was a significant aprepitant by oral oxycodone effect $(\mathrm{F}[4,28]=2.96=.037)$ on heart rate characterized by the highest dose of aprepitant $(200 \mathrm{mg})$ blunting the decline in heart rate at the $40 \mathrm{mg}$ oxycodone dose.

\section{Psychomotor Measures}

All outcomes on the flicker fusion test (ascending and descending frequencies of flicker and mean scores on both trials) were significantly altered as a function of oxycodone dose ( $\mathrm{p} \leq$ 008 for all measures) with virtually no evidence of modulation by aprepitant (data not shown). Similarly, the Maddox Wing test was highly sensitive to oxycodone (both significant dose and time effects were identified for oral and intranasal oxycodone) but was not modified by aprepitant. Finally, oral oxycodone significantly $(F[2,14]=3.8 ; p=.048)$ decreased the absolute number of correct DSST response trials, and a similar trend $(\mathrm{p}=.056)$ was observed for intranasal oxycodone; neither of these findings were altered by active aprepitant. 


\section{Discussion}

This study examined the acute interaction between the $\mathrm{NK}_{1}$ antagonist, aprepitant, and oxycodone when given by the intranasal and oral routes of administration to a cohort of experienced prescription opioid abusers. The results demonstrate that aprepitant significantly enhanced the response to oxycodone (particularly at the higher oxycodone challenge doses) across multidimensional assessments. The most striking enhancements were observed for subjective reports related to abuse liability and positive mood effects (for example, measures of drug liking and estimates of street value). However, observers, who were blinded to the conditions in this randomized study, also provided ratings for signs of opioid agonist effects that were higher when aprepitant $(200 \mathrm{mg}$ ) was given in combination with oxycodone. While the pattern of findings observed for some physiological outcomes was similar to the subject- and observer-rated measures, the magnitude of these effects was modest and generally did not reach statistical significance; all combinations were well tolerated.

Aprepitant has high selectivity for the human $\mathrm{NK}_{1}$ receptor, estimated to be at least 3000fold greater compared to 90 other $\mathrm{G}$ protein-coupled receptors (reviewed in (Kramer et al., 1998). Effective doses for prevention of chemotherapy-induced nausea and vomiting typically range from $80-125 \mathrm{mg}$. Positron emission tomography studies in humans have reported that $\mathrm{NK}_{1}$ receptor occupancy by aprepitant is dose-dependent, with doses of 10, 40 and $300 \mathrm{mg}$ producing approximately $60 \%, 75 \%$, and $90 \%$ occupancy of $\mathrm{NK}_{1}$ receptors in human brain, respectively (Hargreaves, 2002). Based upon these data, one would predict that the test doses in this study (40 and $200 \mathrm{mg}$ ) would have resulted in substantial and biologically relevant dose dependent binding of $275 \%$ of $\mathrm{NK}_{1}$ receptors. Pharmacokinetic studies have shown that peak concentrations of aprepitant are typically achieved about $4 \mathrm{hr}$ after dosing (Majumdar et al., 2006). The timing of the dose procedures in the present study was staggered (with oxycodone dosed $2 \mathrm{hr}$ after aprepitant) with the aim of aligning the peak pharmacodynamic response of oral and intranasal oxycodone (Lofwall et al., 2011; Lofwall et al., 2008; Walsh et al., 2008) with that of aprepitant. Thus, based upon these properties, we are confident that the present study design employed biologically active doses of aprepitant and that the timing of the experimental treatments allowed for examination of the interaction over the period of maximum drug exposure for both aprepitant and oxycodone.

The observed pattern of findings appear to be in contrast with our original hypothesis that aprepitant may reduce the abuse liability of opioids by blunting the response to opioids as preclinical studies might predict (Gadd et al., 2003; Murtra et al., 2000; Ripley et al., 2002). In interpreting these unexpected findings, numerous factors should be considered. First, it is important to recognize that acute dosing with aprepitant may produce different findings compared to chronic dosing, particularly if the underlying mechanism of the interaction observed here is a receptor-mediated event, which can be significantly modified in response to repeated drug exposure. Second, despite the fact that we observed enhanced subjective ratings of oxycodone effects, it is quite plausible that this enhancement could actually lead to a decrease in drug taking behavior. Preclinical self-administration studies have reliably reported an inverted $\mathrm{U}$-shaped function whereby, over a portion of the dose range, selfadministration of drugs with known reinforcing properties increases in a dose-dependent 
fashion; however, at some point as the dose escalates (and presumably the drugs pharmacological action increases), self-administration is decreased (Johanson and Fischman, 1989; Schuster and Johanson, 1981). It has been difficult to demonstrate the parallel finding in the human laboratory, as it is often impossible to test the higher dose range due to safety and ethical constraints. However, there is strong convergent clinical evidence that the use of agonist-type therapies (which produce direct effects similar to those of the drug of abuse) can be effective at reducing drug use with opioids (Strain and Stitzer, 2006), psychomotor stimulants (Herin, Rush and Grabowski, 2010) and nicotine (Henningfield et al., 2005). Future human studies can address this issue by directly examining opioid self-administration after acute and/or chronic treatment with aprepitant.

At least two biological explanations for the unexpected observed findings should be considered. The first arises from the pharmacokinetic profiles of oxycodone and aprepitant, respectively. Oxycodone metabolism primarily occurs through $\mathrm{N}$-demethylation by cytochrome P450 3A4 to noroxycodone, and this pathway is reported to account for more than $50 \%$ of oxycodone elimination by both the oral (Poyhia et al., 1992) and intranasal routes (Lofwall et al., 2011). A secondary pathway for oxycodone metabolism is Odemethylation by P450 2D6 to the active metabolite oxymorphone; however, studies have suggested that its formation plays little, if any, role in the observed pharmacodynamic response to oxycodone in humans (Heiskanen, Olkkola and Kalso, 1998). CYP450 3A4 is also recognized as the primary enzyme responsible for the metabolism of aprepitant (Sanchez et al., 2004). Pharmacokinetic studies assessing metabolism of midazolam as a probe to assess the P450 3A4 activity of aprepitant suggest that the efficacy of aprepitant as an inhibitor of CYP 3A4 may increase with increasing dose. That is, administration of low dose aprepitant $(40 \mathrm{mg})$ in combination with midazolam did not significantly increase midazolam plasma concentrations (AUC increased was 1.2 fold greater than midazolam alone), while administration of a higher aprepitant dose $(125 \mathrm{mg})$ significantly increased midazolam AUC by 2.3 fold (Majumdar et al., 2003). Thus, it is possible in the present study that the higher dose of aprepitant $(200 \mathrm{mg}$ ) produced greater inhibition of P450 3A4 than the lower dose $(40 \mathrm{mg})$. Inhibition of P450 3A4 would decrease the metabolism of oxycodone and increase oxycodone exposure; this may account for the observed enhanced response to oxycodone that was especially evident under the high dose combination conditions. This study did not collect plasma samples and is unable to assess this potential pharmacokinetic interaction, which, in light of the present results, should be addressed in future studies. However, examination of the time action curves and time-to-reach-peak effects (both measures that could be altered in response to a delay or inhibition of oxycodone metabolism) revealed no evidence of a shift in the onset, time-to-peak, or decline of pharmacodynamic effects; rather, the interaction was characterized by an overall elevation in the response across the time course. Furthermore, although only limited doseresponse data were generated, these did not support a simple left-shift of the dose-response curve for oxycodone by aprepitant that would be expected to result from a pharmacokinetic interaction that led to increased plasma concentrations of the opioid agonist. Although not conclusive, this makes it less likely that a pharmacokinetic interaction underlies the observed potentiation of oxycodone effects by the highest aprepitant dose. 
A second more intriguing explanation for the observed findings arises from both our original hypothesis (i.e., that there are critical receptor-based neuropharmacological interactions between $\mathrm{NK}_{1}$ and $m u$ opioid receptors) and from the overall pattern of aprepitant-oxycodone interactions observed here. $\mathrm{NK}_{1}$ and $m u$ opioid receptors are known to be co-localized throughout key regions in the nervous system (Aicher, Punnoose and Goldberg, 2000; Foran et al., 2000; Gadd et al., 2003). In vitro studies have shown that $\mathrm{NK}_{1}$ and $m и$ opioid receptors can interact, resulting in altered $m u$ opioid receptor trafficking and resensitization. This interaction was originally proposed to reflect heterodimerization of $\mathrm{NK}_{1}$ and $m u$ opioid receptors (Pfeiffer et al., 2003). More recent data replicated these functional findings, both in cell lines and in striatal, amygdala and locus coeruleus neurons that naturally co-express $\mathrm{NK}_{1}$ receptors and $m u$ opioid receptors. These experiments also indicated a somewhat different mechanism of action from that originally proposed, in which $\mathrm{NK}_{1}$ receptor activation leads to sequestration of beta-arrestin-2 (BARR2; (Yu et al., 2009). BARR2 is critical for internalization of $т и$ opioid receptors upon their activation by agonists through endocytosis and resulting phosphorylation (Pierce, Premont and Lefkowitz, 2002). It has been proposed that this process is critical for acute opioid tolerance and the addictive actions of exogenous opioid agonists, because $т и$ opioid receptor internalization, dephosphorylation and trafficking back to the cell surface are required for resensitization of receptors in order for them to maintain their ability to transduce agonist driven signaling (Waldhoer, Bartlett and Whistler, 2004). Together, these observations suggest the possibility of an intriguing mechanism underlying the present findings. In this conceptualization, activation by oxycodone leads to rapid partial $т и$ opioid receptor desensitization. Under, placebo pretreatment conditions, endogenous Substance $\mathrm{P} / \mathrm{NK}_{1}$ tone interferes, in part, with $m u$ opioid receptor trafficking and resensitization. Upon blockade of SP/NK1 tone, this interference is removed, allowing a greater degree of resensitized $m и$ opioid receptor recycling to the cell surface, and an upward shift in the plateau for the highest oxycodone doses.

In summary, there is a growing body of evidence that the use of $\mathrm{NK}_{1}$ antagonists may represent a novel strategy for modulating the acute and chronic effects of $m и$ opioid agonists related to abuse liability, tolerance and physical dependence. To date, this is the first controlled proof-of-concept and safety study to examine the interaction between the $\mathrm{NK}_{1}$ antagonist, aprepitant, with a prototypic $m u$ agonist (in this case, oxycodone) in humans. The findings suggest that acute doses of aprepitant can significantly increase the magnitude of $m u$ agonist signs and symptoms in response to oxycodone. Although our study did not address the mechanism underlying this interaction, prior preclinical observations suggest altered $m и$ opioid receptor trafficking and resensitization after agonist activation may account for our findings. Agonist-induced desensitization and tolerance in response to exogenous opioid ligands has been proposed to contribute to their addictive properties (Waldhoer et al., 2004), and it can be speculated that a mechanism that interferes with this process might have therapeutic utility in opioid dependence. At a minimum, our data do suggest a biologically meaningful interaction between these systems that can be observed in humans within the therapeutic dose range and is worthy of further exploration. 


\section{Acknowledgments}

Support for this project was provided by the National Institute on Drug Abuse through grant funding (R01 DA027031; SLW) and through a Clinical and Translational Science Award (CTSA) to the University of Kentucky (UL1RR033173). Merck Sharp \& Dohme Corporation graciously provided aprepitant tablets and matched placebo at no cost through their external grants program. The authors would like to thank the nursing staff at the Clinical Research-DOC, the research staff at the Center on Drug and Alcohol Research and Dr. Stephen Sitzlar at the Investigational Drug Services from the University of Kentucky for their expert services and support for this project. This study was registered at www.clinicaltrials.gov. October 20, 2009 with the identifier NCT00999544.

\section{References}

Aicher SA, Punnoose A, Goldberg A. mu-Opioid receptors often colocalize with the substance P receptor (NK1) in the trigeminal dorsal horn. J Neurosci. 2000; 20:4345-4354. [PubMed: 10818170]

Beck AT, Ward CH, Mendelson M, Mock J, Erbaugh J. An inventory for measuring depression. Arch Gen Psychiatry. 1961; 54:561-571. [PubMed: 13688369]

Birklein F, Schmelz M. Neuropeptides, neurogenic inflammation and complex regional pain syndrome (CRPS). Neurosci Lett. 2008; 437:199-2002. [PubMed: 18423863]

Costa, PT.; McCrae, RR. The NEO Personality Inventory Manual. Psychological Assessment Resources; Odessa, Florida: 1985.

Dando TM, Perry CM. Aprepitant: A review of its use in the prevention of chemotherapy-induced nausea and vomiting. Drugs. 2004; 64:777-794. [PubMed: 15025555]

De Felipe C, Herrero JF, O'Brien JA, Palmer JA, Doyle CA, Smith AJH, Laird JMA, Belmonte C, Cervero F, Hunt SP. Altered nociception, analgesia and aggression in mice lacking the receptor for substance P. Nature. 1998; 405:180-183. [PubMed: 10821273]

Derogatis, LR. SCL-90-R. Administration, Scoring and Procedures Manual II. 2. Clinical Psychometric Research; Baltimore: 1983.

Ebner K, Singewald N. The role of substance P in stress and anxiety responses. Amino Acids. 2006; 31:251-272. [PubMed: 16820980]

Foran SE, Carr DB, Lipkowski AW, Maszczynska I, Marchand JE, Misicka A, Beinborn M, Kopin AS, Kream RM. A substance P-opioid chimeric peptide as a unique nontolerance-forming analgesic. Proc Natl Acad Sci U S A. 2000; 97:7621-7626. [PubMed: 10852965]

Fraser HF, Van Horn GG, Martin WR, Wolbach AB, Isbell H. Methods for evaluating addiction liability. (A) "Attitude of opiate addicts toward opiate-like drugs, (B) A short-term "direct" addiction test. J Pharmacol Exper Ther. 1961; 133:371-378. [PubMed: 13701509]

Gadd CA, Murtra P, De Felipe C, Hunt SP. Neurokinin-1 receptor-expressing neurons in the amygdala modulate morphine reward and anxiety behaviors in the mouse. J Neurosci. 2003; 23:8271-8280. [PubMed: 12967989]

George DT, Gilman J, Hersh J, Thorsell A, Herion D, Geyer C, Peng X, Kielbasa W, Rawlings R, Brandt JE, Gehlert DR, Tauscher JT, Hunt SP, Hommer D, Heilig M. Neurokinin 1 receptor antagonism as a possible therapy for alcoholism. Science. 2008; 319:1536-1539. [PubMed: 18276852]

Hargreaves R. Imaging substance P receptors (NK1) in the living brain using positron emission tomography. J Clin Psychiatry. 2002; 63:18-24. [PubMed: 12562139]

Hasenohrl RU, Gerhardt P, Huston JP. Naloxone blocks conditioned place preference induced by substance $P$ and [pGlu6]-SP(6-11). Regul Pept. 1991; 35:177-187. [PubMed: 1722047]

Hasenohrl RU, Gerhardt P, Huston JP. Positively reinforcing effects of the neurokinin substance P in the basal forebrain: Mediation by its C-terminal sequence. Exp Neurol. 1992; 115:282-291. [PubMed: 1370940]

Heiskanen T, Olkkola KT, Kalso E. Effects of blocking CYP2D6 on the pharmacokinetics and pharmacodynamics of oxycodone. Clin Pharmacol Ther. 1998; 64:603-611. [PubMed: 9871425]

Henningfield JE, Fant RV, Buchhalter AR, Stitzer ML. Pharmacotherapy for nicotine dependence. CA Cancer J Clin. 2005; 55:281-299. quiz 322-283, 325. [PubMed: 16166074] 
Herin DV, Rush CR, Grabowski J. Agonist-like pharmacotherapy for stimulant dependence: preclinical, human laboratory, and clinical studies. Ann N Y Acad Sci. 2010; 1187:76-100. [PubMed: 20201847]

Herpfer I, Lieb K. Substance P receptor antagonists in psychiatry. CNS Drugs. 2005; 19:275-293. [PubMed: 15813642]

Hill R. Substance P, opioid and catecholamine systems in the mouse central nervous system (CNS). Proc Natl Acad Sci U S A. 2002; 99:549-551. [PubMed: 11805310]

Huang S-C, Korlipara VL. Neurokinin-1 receptor antagonists: A comprehensive patent survey. Expert Opin Ther Patents. 2010; 20:1019-1045.

Johanson C-E, Fischman MW. The pharmacology of cocaine related to its abuse. Pharmacol Rev. 1989; 41:3-52. [PubMed: 2682679]

King T, Ossipov MH, Vanderah TW, Porreca F, Lai J. Is paradoxical pain induced by sustained opioid exposure an underlying mechanism of opioid antinociceptive tolerance? Neurosignals. 2005; 14:194-205. [PubMed: 16215302]

Kramer MS, Cutler N, Feighner J, Shrivastava R, Carman J, Sramke JJ, Reines SA, Liu G, Snavely D, Wyatt-Knowles E, Hale JJ, Mills SG, MacCoss M, Swain CJ, Harrison T, Hill RG, Hefti F, Scolnick EM, Cascieri MA, Chicchi GG, Sadowski S, Williams AR, Hewson L, Smith D, Carlson EJ, Hargreaves R, Rupniak NMJ. Distinct mechanism for antidepressant activity by blockade of central substance P receptors. Science. 1998; 11:1640-1645. [PubMed: 9733503]

Lofwall MR, Moody DE, Fang WB, Nuzzo PA, Walsh SL. Pharmacokinetics of intranasal crushed OxyContin and intravenous oxycodone in nondependent prescription opioid abusers. J Clin Pharmacol. 2011 e-pub ahead of print.

Lofwall, MR.; Nuzzo, PA.; Tuttle, JP.; Walsh, SL. College on Problems of Drug Dependence. San Juan; Puerto Rico: 2008. Effects of cold pressor pain on cortisol stress response and abuse liability of intranasal Oxycontin ${ }^{\circledR}$ in non-dependent prescription opioid abusers. In.

Mai JK, Stephens PH, Hopf A, Cuello AC. Substance P in the human brain. Neuroscience. 1986; 17:709-739. [PubMed: 2422595]

Majumdar AK, Howard L, Goldberg MR, Hickey L, Constanzer M, Rothenberg PL, Crumley TM, Panebianco D, Bradstreet TE, Bergman AJ, Waldman SA, Greenberg HE, Butler K, Knops A, De Lepeleire I, Michiels N, Petty KJ. Pharmacokinetics of aprepitant after single and multiple oral doses in healthy volunteers. J Clin Pharmacol. 2006; 46:291-300. [PubMed: 16490805]

Majumdar AK, McCrea JB, Panebianco DL, Hesney M, Dru J, Constanzer M, Goldberg MR, Murphy G, Gottesdiener KM, Lines CR, Petty KJ, Blum RA. Effects of aprepitant on cytochrome P450 3A4 activity using midazolam as a probe. Clin Pharmacol Ther. 2003; 74:150-156. [PubMed: 12891225]

Maldonado R, Girdlestone D, Roques BP. RP 67580, a selective antagonist of neurokinin-1 receptors, modifies some of the naloxone-precipitated morphine withdrawal signs in rats. Neurosci Lett. 1993; 156:135-140. [PubMed: 7692360]

Martin WR, Sloan JW, Sapira JD, Jasinski DR. Physiologic, subjective, and behavioral effects of amphetamine, methamphetamine, ephedrine, phenmetrazine, and methylphenidate in man. Clin Pharmacol Ther. 1971; 12:245-258. [PubMed: 5554941]

McLellan AT, Kushner H, Metzger D, Peters R, Smith I, Grisson G, Pettinati H, Argeriou M. The fifth edition of the Addiction Severity Index. J Subst Abuse Treat. 1992; 9:199-213. [PubMed: 1334156]

McLeod D, Griffiths RR, Bigelow GE, Yingling J. An automated version of the digit symbol substitution test (DSST). Behav Res Methods Instrum. 1982; 14:463-466.

Murtra P, Sheasby AM, Hunt SP, De Felipe C. Rewarding effects opiates are absent in mice lacking the receptor for substance P. Nature. 2000; 405:180-183. [PubMed: 10821273]

Nakade S, Ohno T, Kitagawa J, Hashimoto Y, Katayama M, Awata H, Kodama Y, Miyata Y. Population pharmacokinetics of aprepitant and dexamethasone in the prevention of chemotherapyinduced nausea and vomiting. Cancer Chemother Pharmacol. 2008; 63:75-83. [PubMed: $18317761]$ 
Nomura H, Shiosaka S, Tohyama M. Distribution of substance P-like immunoreactive structures in the brainstem of the adult human brain: an immunocytochemical study. Brain Res. 1987; 404:365370. [PubMed: 2436709]

Pfeiffer M, Kirscht S, Stumm R, Koch T, Wu D, Laugsch M, Schroder H, Hollt V, Schulz S. Heterodimerization of Substance $\mathrm{P}$ and u-opioid receptors regulates receptor trafficking and resensitization. J Biol Chem. 2003; 278:51630-51637. [PubMed: 14532289]

Pierce KL, Premont RT, Lefkowitz RJ. Seven-transmembrane receptors. Nat Rev Mol Cell Biol. 2002; 3:639-650. [PubMed: 12209124]

Poyhia R, Seppala T, Olkkola KT, Kalso E. The pharmacokinetics and metabolism of oxycodone after intramuscular and oral administration to healthy subjects. Br J Clin Pharmacol. 1992; 33:617-621. [PubMed: 1389934]

Preston KL, Bigelow GE, Liebson IA. Comparative evaluation of morphine, pentacozine and ciramadol in postaddicts. J Pharmacol Exper Ther. 1987; 240:900-910. [PubMed: 3559982]

Ripley TL, Gadd CA, De Felipe C, Hunt SP, Stephens DN. Lack of self-administration and behavioural sensitisation to morphine, but not cocaine, in mice lacking NK1 receptors. Neuropharmacology. 2002; 43:1258-1268. [PubMed: 12527475]

Rubenstein EB, Slusher BS, Rojas C, Navari RM. New approaches to chemotherapy-induced nausea and vomiting: From neuropharmacology to clinical investigations. J Cancer. 2006; 12:341-347.

Sanchez RI, Wang RW, Newton DJ, Bakhtiar R, Lu P, Chiu SH, Evans DC, Huskey SE. Cytochrome $\mathrm{P} 4503 \mathrm{~A} 4$ is the major enzyme involved in the metabolism of the substance $\mathrm{P}$ receptor antagonist aprepitant. Drug Metab Disp. 2004; 32:1287-1292.

Santarelli L, Gobbi G, Blier P, Hen R. Behavioral and physiologic effects of genetic or pharmacologic inactivation of the substance P receptor (NK1). J Clin Psychiatry. 2002; 63:11-17. [PubMed: 12562138]

Schuster CR, Johanson C-E. An analysis of drug-seeking behavior in animals. Neurosci Biobehav Rev. 1981; 5:315-323. [PubMed: 7029360]

Strain, EC.; Stitzer, ML. The Treatment of Opioid Dependence. The Johns Hopkins University Press; Baltimore: 2006.

Trang T, Quirion R, Jhamandas K. The spinal basis of opioid tolerance and physical dependence: Involvement of calcitonin gene-related peptide, substance $\mathrm{P}$, and arachidonic acid-derived metabolites. Peptides. 2005; 26:1346-1355. [PubMed: 16042975]

von Euler US, Gaddum JH. An unidentified depressor substance in certain tissue extracts. J Physiol. 1931; 72:74-87. [PubMed: 16994201]

Waldhoer M, Bartlett SE, Whistler JL. Opioid receptors. Annu Rev Biochem. 2004; 73:953-990. [PubMed: 15189164]

Walsh SL, Nuzzo PA, Lofwall MR, Holtman JR Jr. The relative abuse liability of oral oxycodone, hydrocodone and hydromorphone assessed in prescription opioid abusers. Drug Alcohol Depend. 2008; 98:191-202. [PubMed: 18606504]

Yu YJ, Arttamangkul S, Evans CJ, WIlliams JT, von Zastrow M. Neurokinin 1 receptors regulate morphine-induced endocytosis and densitization of $\mu$-opioid receptors in CNS neurons. J Neurosci. 2009; 29:222-233. [PubMed: 19129399] 

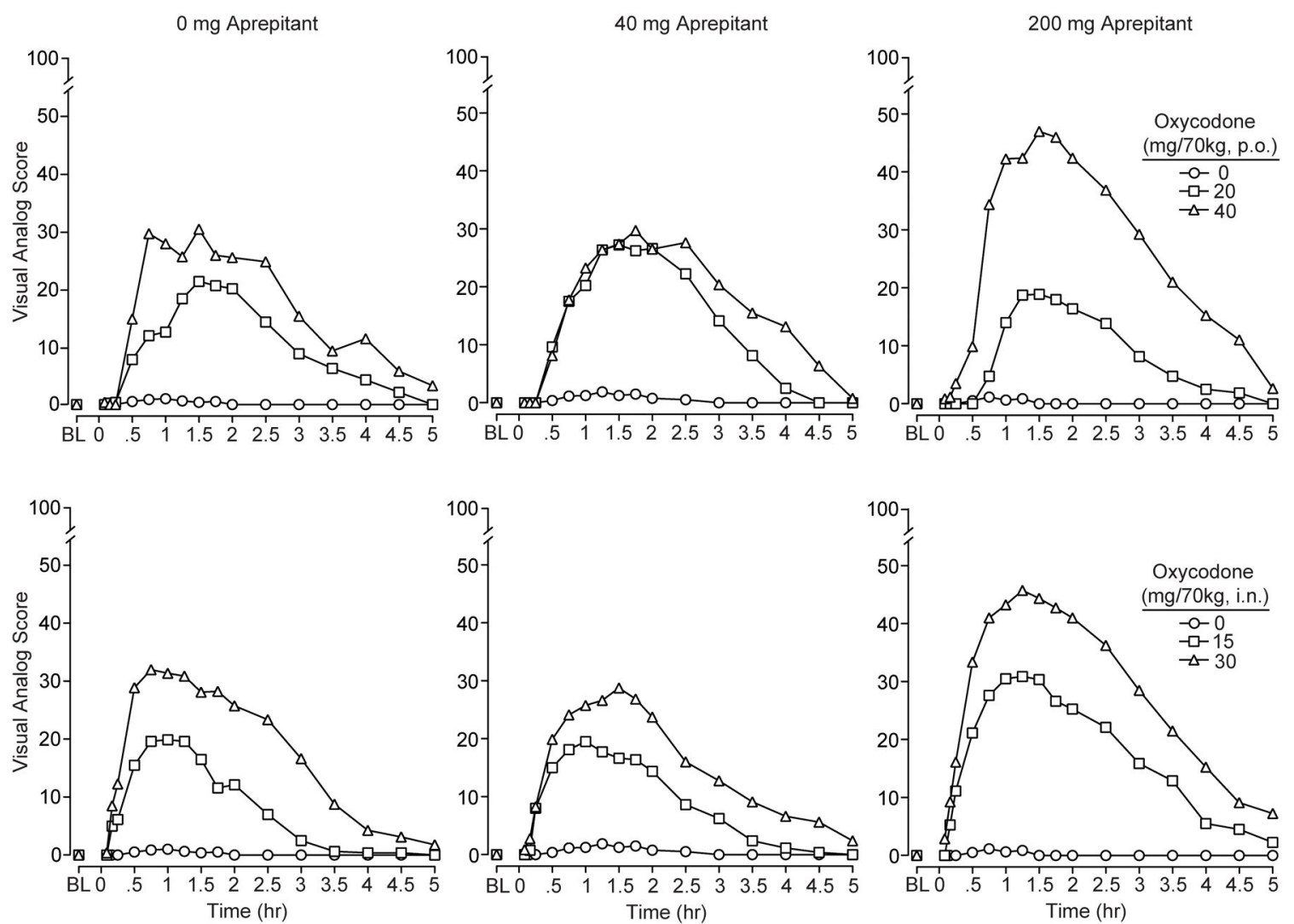

Figure 1.

Mean values ( $\mathrm{n}=8)$ for the visual analog scale "How much do you LIKE the drug?" as rated by the participants are shown for oral (top row) and intranasal (bottom row) oxycodone as a function of 2-hr pretreatment dose of aprepitant at $0 \mathrm{mg}$ (left column), $40 \mathrm{mg}$ (middle column) and $200 \mathrm{mg}$ (bottom column). Statistical analyses revealed significant main effects of oral $(F[2,14]=31.8 ; \mathrm{p}<.001)$ and intranasal oxycodone $(F[2,14]=36.9 ; \mathrm{p}<.001)$ as well as significant time dependent effects ( $\mathrm{df} 16,112 ; \mathrm{p}<.001)$ for both routes $(\mathrm{F}=16.6$ p.o., \& $\mathrm{F}=$ 21.5 i.n.). 


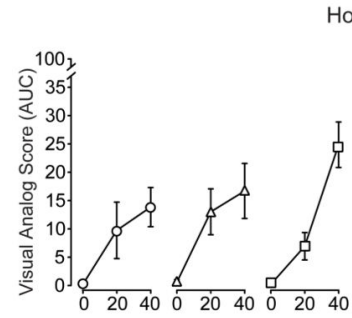

How HIGH are you?

Does the drug have any GOOD effects?
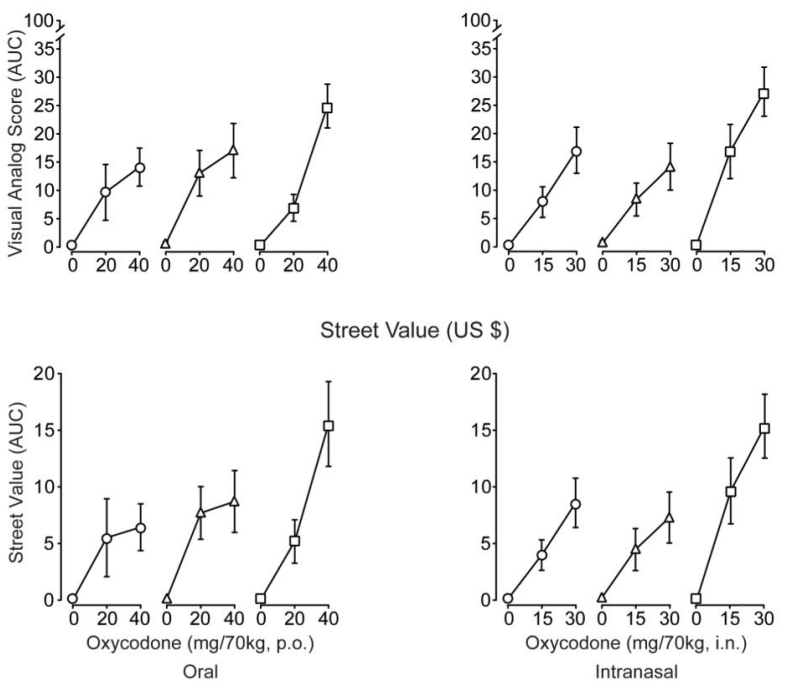

Street Value (US \$)

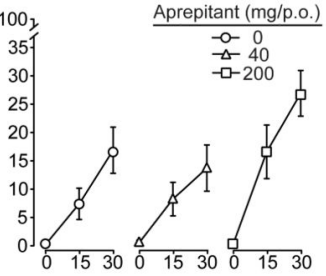

Figure 2.

Mean AUC values ( $n=8, \pm 1$ S.E.M.) for the visual analog scales "How high do you feel?" (top row) and "Does the drug have any good effects?" (middle row) are depicted after oral (left column) and intranasal oxycodone (right column). For ratings of "high," there were significant main effects of oxycodone dose by both routes $(F[2,14]=40.4 ; \mathrm{p}<.001$ oral; $\mathrm{F}=42 ; \mathrm{p}<.001$ intranasal). A significant aprepitant by oxycodone dose effect $(\mathrm{F}[4,28]=2.9$; $\mathrm{p}=.039$, p.o. $)$ and a main effect of aprepitant ( $\mathrm{F}[2,14]=7.1 ; \mathrm{p}=.007$ i.n.) were also observed for ratings of "high." For the measure of "good effects," oxycodone produced significant dose-related increases after both oral $(\mathrm{F}[2,14]=42.8 ; \mathrm{p}<.001)$ and intranasal dosing $(\mathrm{F}[2,14]=40.6 ; \mathrm{p}<.0001)$ along with significant aprepitant $\times$ oxycodone interactions $(F[4,28]=2.9 ; p=.041$, p.o $)$ or main effects of aprepitant $(F[2,14]=6.8 ; p=.009$, i.n. $)$. For Street Value estimates, both oral $(\mathrm{F}[2,14]=29.5 ; \mathrm{p}<.001)$ and intranasal $(\mathrm{F}[2,14]=38 ; \mathrm{p}<.001)$ oxycodone produced significant dose-related increases in dollar value (and placebo was valued at zero). Significant interaction or main effects of aprepitant were observed with both oral $(F[4,28]=3.4 ; p=.023)$ and intranasal oxycodone $(F[2,14]=8.7 ; p=.004)$, whereby street values were higher after $200 \mathrm{mg}$ aprepitant pretreatment compared to placebo. 


\section{Subject-rated Agonist Scale}

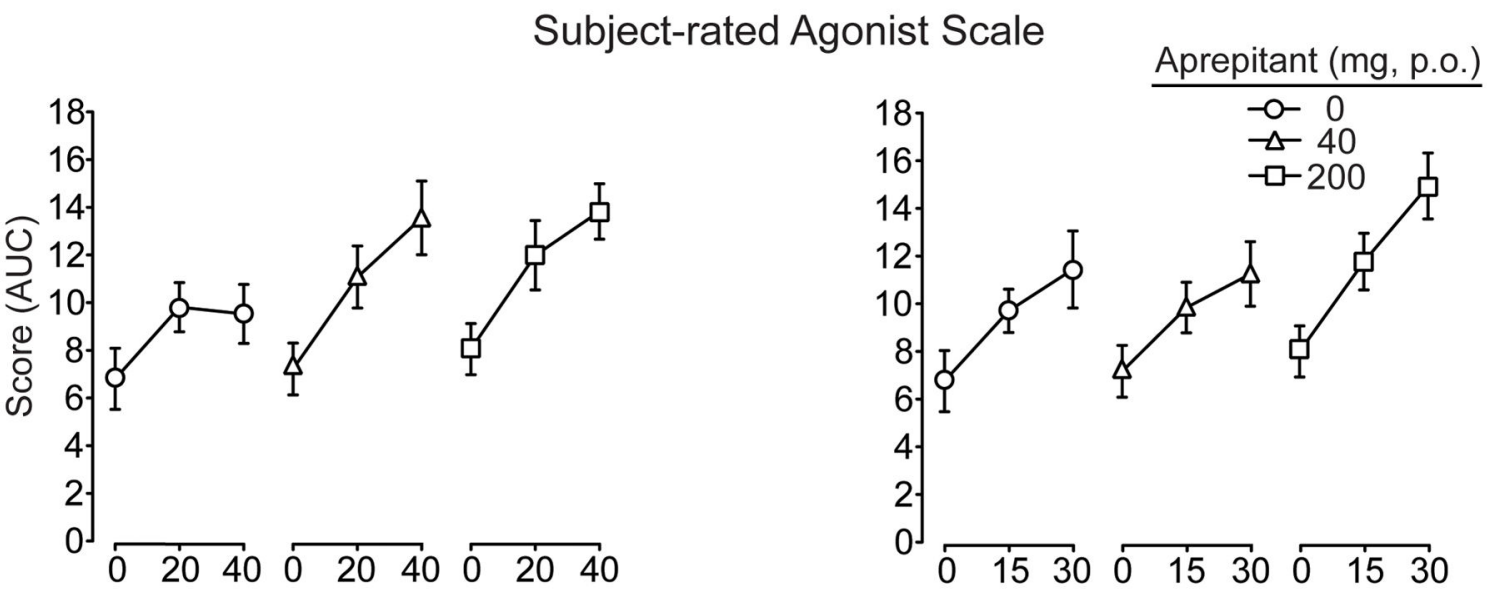

Observer-rated Agonist Scale
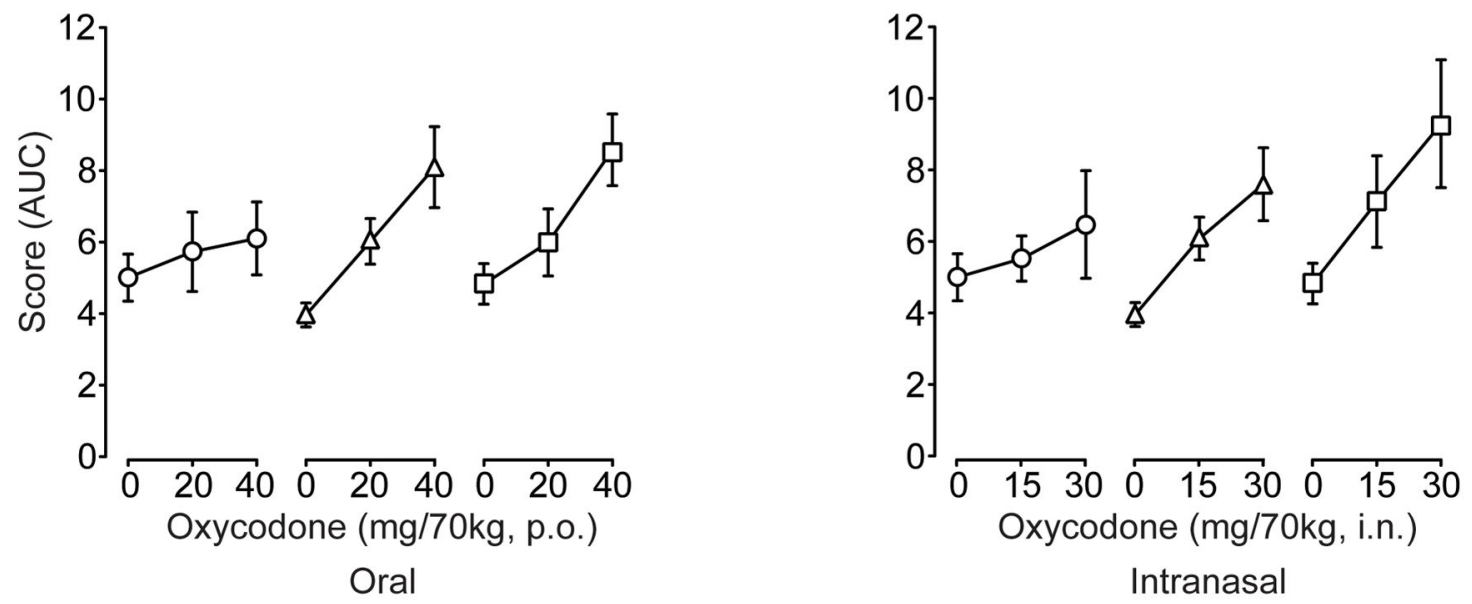

Figure 3.

Data are shown for the composite Opioid Agonist Adjective Scale rated by the subjects (upper panel; maximum possible score 68) and the observers (lower panel; maximum possible score 48) after challenge with oral (left column) and intranasal (right column) oxycodone. Data $(\mathrm{n}=8)$ are presented as AUC values $( \pm 1$ S.E.M). The subject-rated scale revealed significant main effects of oral $(\mathrm{F}[2,14]=25.7 ; \mathrm{p}<.0001)$ and intranasal $(F[2,14]=29.8 ; \mathrm{p}<.0001)$ oxycodone and significant main effects of aprepitant $(\mathrm{F}[2,14]=7$; $\mathrm{p}=.008$, oral; $\mathrm{F}[2,14]=7 ; \mathrm{p}=.008$, intranasal). The observer-rated scale revealed significant main effects of oral $(F[2,14]=18.6 ; \mathrm{p}<.001)$ and intranasal $(\mathrm{F}[2,14]=12 ; \mathrm{p}=.001)$ oxycodone but no main or interaction effects with aprepitant. 


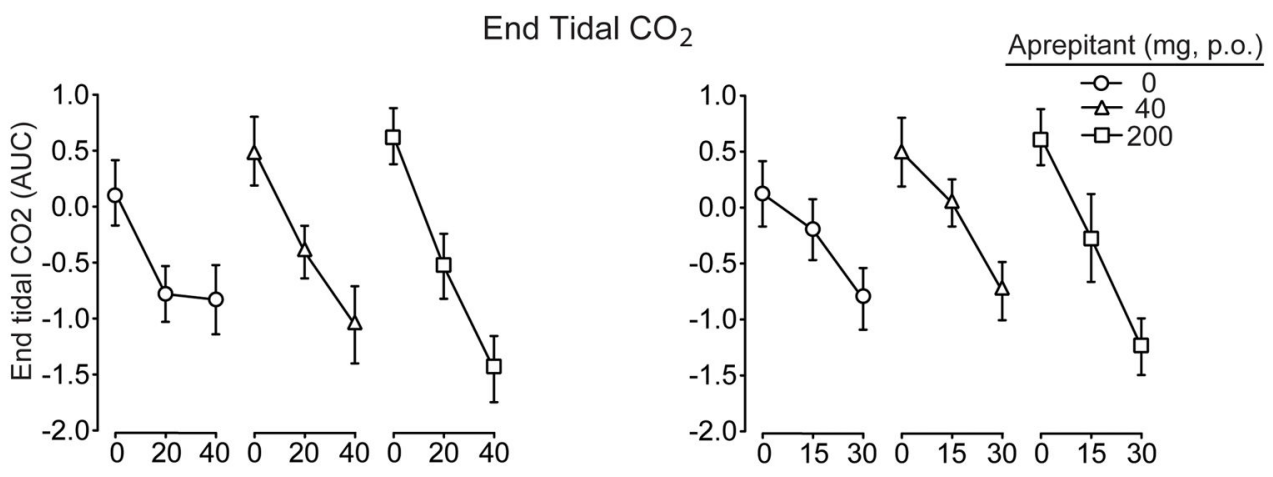

Pupil Diameter
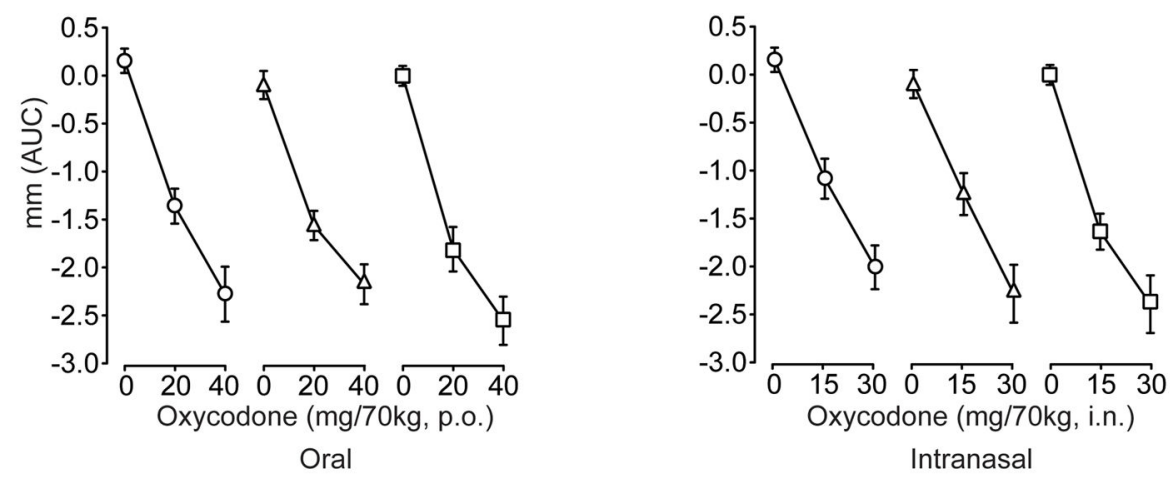

Figure 4.

Data are shown for end-tidal $\mathrm{CO}_{2}$ concentrations (upper panel) and pupil diameter (lower panel) after challenge with oral (left column) and intranasal (right column) oxycodone. Data $(\mathrm{n}=8)$ are presented as AUC values generated from change-from-baseline time course data $( \pm 1$ S.E.M $)$. Both oral $(F[2,14]=49.3 ; p<.001)$ and intranasal $(F[2,14]=29.7 ; p<.001)$ oxycodone produced significant increases in end-tidal $\mathrm{CO}_{2}$ as shown, but aprepitant produced only a trend $(\mathrm{p}=.095)$ to further increase $\mathrm{CO}_{2}$ after oral oxycodone. Both oral $(\mathrm{F}[2,14]=174.1 ; \mathrm{p}<.001)$ and intranasal oxycodone $(\mathrm{F}[2,14]=121.5 ; \mathrm{p}<.001)$ produced significant dose-related decreases in pupil diameter (lower panels), but no main or interaction effects for aprepitant were observed. 


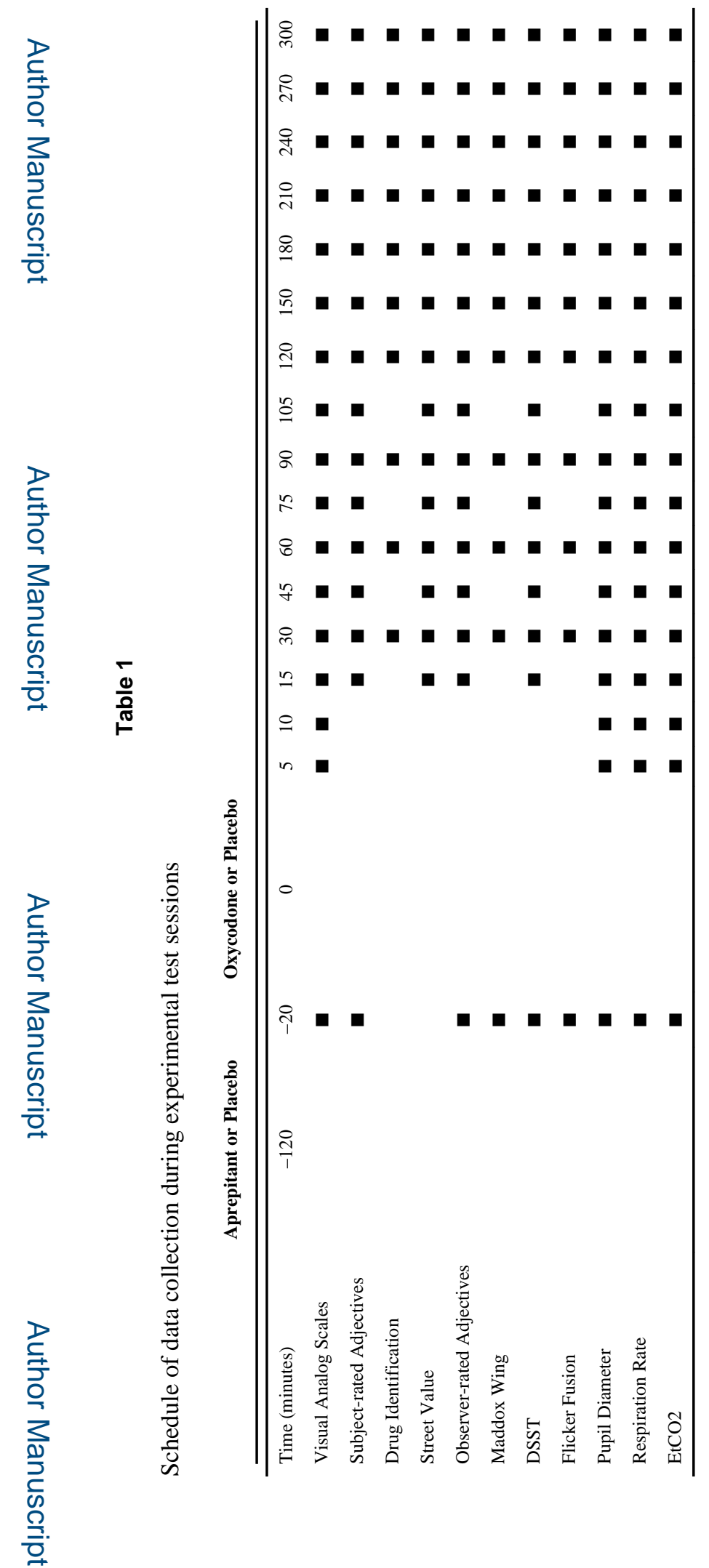

Addict Biol. Author manuscript; available in PMC 2015 March 10. 